\title{
ADDITIVE MANUFACTURING RESEARCH LANDSCAPE: A LITERATURE REVIEW
}

\author{
Schmitt, Pascal; \\ Zorn, Stefan; \\ Gericke, Kilian \\ University of Rostock
}

\begin{abstract}
Additive manufacturing offers several potentials such as the freedom of design, part consolidation, function integration, or time and cost-savings. These potentials make AM interesting for industries such as aerospace, automotive and medical implants, and are also seen as enables for the creation of entirely new business models. Additive manufacturing has the potential to change the current manufacturing landscape substantially and has attracted much attention of industry and academia over the last decades.

However, these developments require improvements concerning the technology itself and its successful implementation into the value creation chain. Driven by the promising market opportunities and upcoming technological developments, many research activities started.

This paper presents a literature review of publications from the last 20 years. Based on this analysis, the evolution of the AM research landscape is portrayed. The research landscape is organised into four areas: machine and process, material, digital process chain and methodology. The paper summarises developments in each of these areas and concludes by presenting current and discussing future research topics.
\end{abstract}

Keywords: Additive Manufacturing, Design for Additive Manufacturing (DfAM), 3D printing

\section{Contact:}

Schmitt, Pascal

University of Rostock

Faculty of Mechanical Engineering and Marine Technology

Germany

pascal.schmitt@uni-rostock.de 


\section{INTRODUCTION}

Additive Manufacturing (AM) offers a variety of potentials and advantages, such as the freedom of design (Ngo et al., 2018; François et al., 2019), which is seen as an enabler for lightweighting (Gibson et al., 2015; Kussmaul et al., 2019), part consolidation (Yang et al., 2015) or function integration (Gorn et al., 2019). Furthermore, it offers time and cost-saving potentials, e.g. by eliminating process steps, lighter (material-saving) components, or the omission of expensive tools (Gebhardt and Hötter, 2016). Time-savings are enabled by an acceleration of the whole product development process, as the integration of $3 \mathrm{D}$ CAD and AM is seamless. Thus data conversion or interpretation of the design intent is less problematic (Gibson et al., 2015). Further potentials are mass customisation, the use of multiple or architectured materials or a reduction of the environmental impact due to less waste and use of material and energy during production (Gibson et al., 2015; Durakovic, 2018). These potentials made AM interesting for branches such as Aerospace, Automotive and Medical Implant Industries (Bourell et al., 2009; Parthasarathy et al., 2011; Allison and Scudamore, 2013; RAE, 2013; Ceulemans et al., 2020). However, AM also allows the creation of entirely new business models like the local creation of spare parts on demand (Ehrenberg, 2013).

The fast uptake of AM in industry, as well as in educational institutions and for private use, is due to the development of affordable devices and open design solutions (RepRap, 2013; AMFG, 2020) after the expiration of a patent on Fused Deposition Modelling in 2009 (RAE, 2013). The expiration of a Laser Sintering patent in 2014 is causing similar effects (Kessler et al., 2020). However, the costs of SLS benchtop printers remain substantially higher compared to FDM printers.

Along the value chain, various sectors can benefit from the growth in Additive Manufacturing, including, e.g. producers of raw material, manufacturers of 3D printing machines and components, software developers, as well as companies and businesses making use of these technologies (Valdes, 2017; AMFG, 2020). The forecasts and descriptions of the potentials range from modest improvements in some areas to the announcement of a new industrial revolution (de Vere, 2013). The global market volume is estimated at more than six billion US dollars in 2016, with double-digit growth rates and expected to reach almost 33 billion US dollars by 2023 (Markets\&Markets, 2019). Thus, AM is expected to have substantial economic potential.

Even though Additive Manufacturing (AM) has been called the next industrial revolution already for many years (Anderson, 2012; RAE, 2013) and expected to result in a democratisation of production, it faces some significant hurdles for successful commercialisation (RAE, 2013). A decade ago, the quality of parts, process reliability, part size, speed, price, and design support were considered major issues (Bourell et al., 2009; Allison and Scudamore, 2013). In response to these issues, driven by the promising market opportunities and upcoming technological developments, several research consortia were established around the world, and standardisation committees formed (Beaman et al., 2004; Allison and Scudamore, 2013).

A decade later, it is time to analyse how the field of AM has evolved, both concerning research and its uptake and dissemination in industry. Therefore, this paper aims to provide first answers to the following research questions:

1. How has the research landscape in the field of AM evolved in the last decade?

2. What are current areas and design-related topics that need further research in the future?

\section{STUDY DESIGN}

First answers to these research questions are derived from a literature study. The study aims to identify the evolution of related trends, challenges and barriers and to provide an overview of the current status. Different research methods were combined as it became clear early in the process that the body of knowledge is relatively large. For the initial screening of the topic of additive manufacturing, we analysed AM-related scientific publications of the last 20 years (from 2000 to 2020) listed on Scopus. To define the database for our analysis, we used the following keywords, which are defined in the DIN ISO EN/ASTM 52900 to describe AM-related research: Additive Manufacturing and listed historical terms such as additive fabrication, -techniques, -layer manufacturing, and solid freeform fabrication. 3D printing (in different variations) and Rapid Prototyping and Rapid Tooling were also included as keywords. Besides, the following terms not listed in the standard were added: Rapid Manufacturing, Direct Tooling, Direct Manufacturing, Direct Prototyping, and Additive Repair. 
Following the first screening of the literature, the database was more closely examined. Details on the search terms used for the detailed investigation can be found in the sections of the respective topics. After selecting papers based on their title and abstract, the remaining publications were analysed by skim reading. The initial search was complemented by a review of established works in the area (e.g. Gebhardt, 2011; Gibson et al., 2015) and the design society database.

Furthermore, the number of patent applications for the period 2000 to 2018 is analysed. The number of patent applications is based on a study conducted by the European Patent Organisation (EPO). It includes applications filed directly with the EPO or international application (Patent Cooperation Treaty - PCT) that entered into the European phase in that period (Ceulemans et al., 2020). The patent analysis was carried out using a simple counting method. For this purpose, the field ranges of the Cooperative Patent Classification (CPC) scheme were identified in which the AM related patent is located. A detailed description can be found in the following source (Ceulemans et al., 2020).

\section{FINDINGS}

\subsection{An overview of scientific publications and patent applications}

The mentioned search string (see Study Design) was used for the initial screening of the topic of additive manufacturing. A simple counting method was used. A total amount of 72059 AM-related scientific publications were found. The results for the period from 2000 to 2018 are shown as absolute publication frequency per year in Figure 1. This dataset serves as the basis for our further investigation. Its composition was examined in the process of the work.

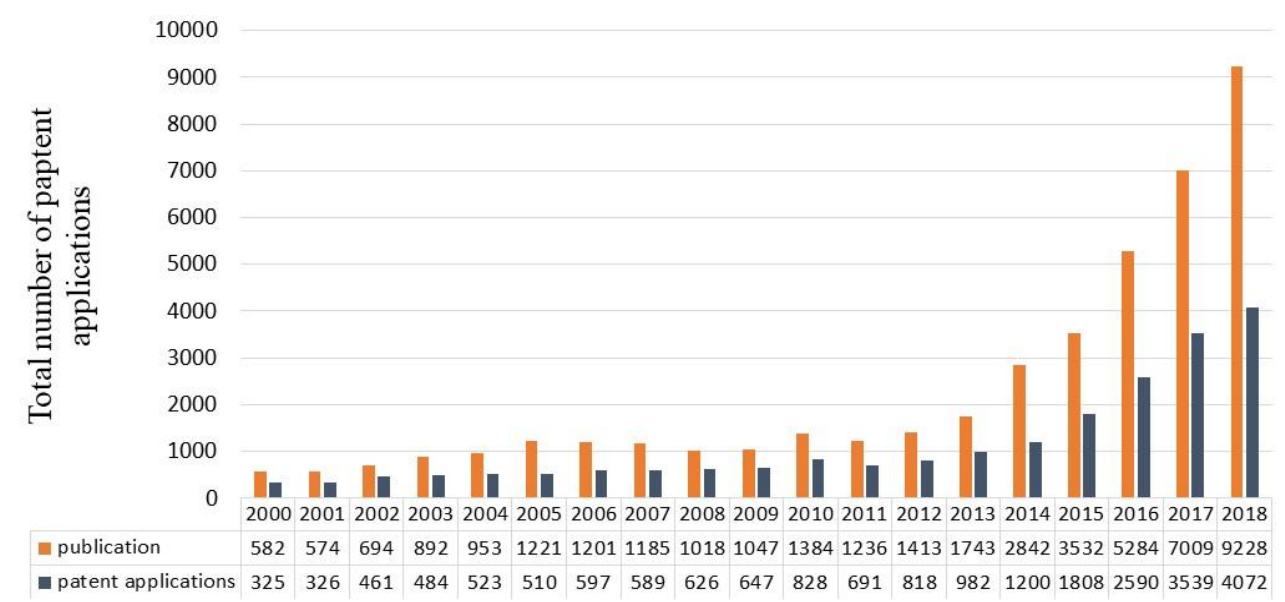

Figure 1. AM-related patent application and research publication in the period 2000 to 2018

\section{Patents}

The study by the European Patent Office (Ceulemans et al., 2020) shows steady growth in AM patenting activity from 2000 to 2018. In 2000, 335 applications were filed. This amount increased up to 828 in 2010. After 2011, patent applications increased substantially. The annual rate of AM related patent applications has increased by $36 \%$ on average during the years 2015 to 2018, with a total number of 4072 patents in 2018 alone. The largest share of patent applications in AM (50\%) was accounted for industrial applications. $80 \%$ of scientific publications considered in this study and $60 \%$ (excluding 2019 and 2020) of AM-related patents were filed after 2011.

\subsection{Research landscape}

The use of AM technology for producing fully functional parts is a complex field requiring knowledge of different areas. On the one hand, there are requirements and constraints from the market and the respective product application domain. On the other hand, there is a variety of materials available, which differ in type, form, and state and are therefore linked to certain AM-processes and machines. These require differently prepared model data or process-dependent control parameters, which are provided and controlled via the digital process chain. Furthermore, DfAM methodology offers different types of support to designers. To be able to utilise the AM-related potentials in product development, the interrelationships must be investigated. This results in a variety of research fields 
which are shown in Figure 2. The classification is based on the four categories of the AM technology cartography created by the EPO in 2020 (Ceulemans et al., 2020).

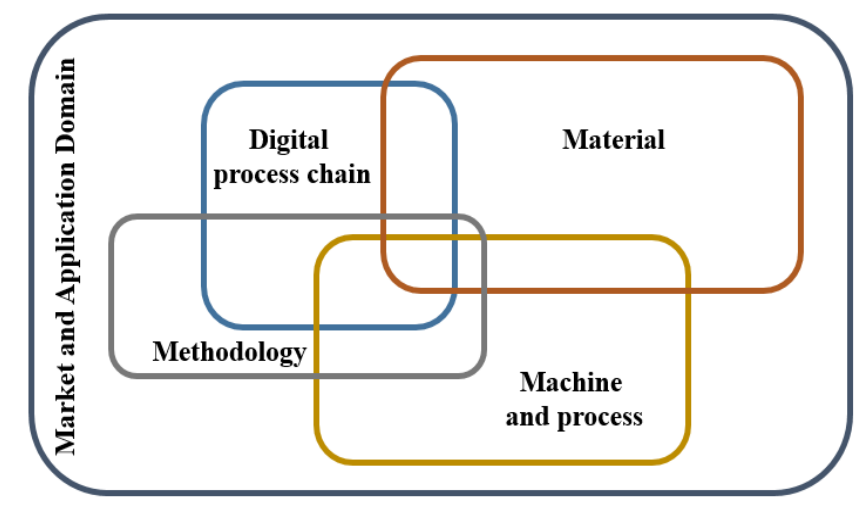

Figure 2. AM technologies and research landscape

Figure 2 consists of five elements. The first element symbolises the general market situation and also the influence of the respective application domains. Machine and process address the additive manufacturing processes and associated machines, which are highly influenced by the required materials and the digital process chain. The material contains the different types, forms, and shapes of AM material as input for the AM process with their specific machines. The digital process chain includes all technology and research aspects related to digitised manufacturing and the handling of the digital representation of the product. The digital representation can be a model designed or optimised via software. Furthermore, processes are included which aim to monitor and control the manufacturing process. All approaches that incorporate AM-related knowledge effects into the product development process can be found in the methodology section.

\subsection{Topics}

The screening of the AM landscape indicates the number of publications in a respective AM related research area. Due to the search algorithm, a publication can be counted in multiple areas if the keywords match. The next closer look for every topic is needed to see specific trends in the individual groups.

\subsubsection{AM machine and Processes}

Building physical 3D geometries by successive adding of the material makes the products properties highly dependent on the type of machine and AM process. Regarding the process used to join the feedstock material, ASTM (2017) classified seven categories, namely Binder Jetting (BJ), Direct Energy Deposition (DED), Material Extrusion (ME), Material Jetting (MJ), Powder Bed Fusion (PBF), Sheet Lamination (SL) and Vat Polymerisation (VP). The intended product properties can, therefore, only be determined by taking a holistic view of the machine type, process parameters, and part orientation during the manufacturing process. Additionally, single-step or multi-step additive processes, as well as pre-and post-processing operations, can be distinguished.

In recent years, there has been an enormous increase of hardware manufacturers for AM devices, with about 130 different hardware manufacturers on the market in 2020 (AMFG, 2020). These are not just start-ups with new technologies that are entering the market, but instead also established companies with continuous upgrades of their machines and processes, resulting in a variety of different and even faster and more reliable machines. Besides the high-end industrial systems, a wide range of desktop 3D printers has been developed, and a transfer of industrial features (e.g., heated chamber or dual extrusion) can be observed, resulting in a better quality of printing. They have become a vital part of the industrial AM landscape as an entry-point into AM production.

The most commonly spread systems are polymer and metal-based. In 2019, $72 \%$ of the companies studied used polymer-based, and $49 \%$ used metal-based AM-systems (Ernst \& Young, 2019).

The categorised AM processes focus on homogeneous material. Recent developments are in the field of processes that handle multiple materials (Zhang et al., 2018) to form composite systems, especially fibre-reinforced composites. Composite systems are a new rising segment. The first marked-ready fibre-reinforced composite desktop solutions were announced in 2019. Today the composite 3D printing market is valued at around 2.7 billion US Dollar (AMFG, 2020). 
The use of multiple materials in a single print is accompanied by several challenges that have prompted current research not only in the field of AM processes and machines. It is closely linked to the digital process chain and current material research. Furthermore, new challenges emerge around material processing. Bioprinting represents a particular area here, and current research is focusing on preserving and supporting biomaterials and on keeping them sterile.

\subsubsection{Materials}

AM processes depend on the material. The material plays a significant role because type, form, and state are linked to specific technologies. One of the oldest and most commonly spread materials are polymers and metal. The current market share of polymer material is around $80 \%$ (Sculpteo, 2020).

However, there is a rapidly growing number and variety of 3D printing materials on the market: polymers, metals, resins, rubbers, ceramics, glass, sand, concretes, food, live cells, biomaterials, and compound materials. There are also various forms such as powder, paste, wire, pellets, liquidity, or foil. In December 2020, the Senvol Material Database listed 3248 materials (Senvol, 2020) compared to slightly over 1700 materials in the previous year. Depending on the source, there are different classifications for 3D printing materials available on the market. Essentially, the materials can be divided into four main groups: metals, polymers, ceramics, and composites (Tofail et al., 2018; ASTM International, 2019). Alternatively, these materials can be subdivided into biomaterial, functionally graded materials (Tofail et al., 2018), or cement (Lowke et al., 2018).

The AM related research landscape (see Section 3.2) was examined with regard to the mentioned main groups. The respective material groups were characterised by the following keywords, which also served as search terms: metal and alloy, polymer, ceramic, composite, and biomaterial. Multiple assignments of individual publications were possible. The distribution of publications is shown in Figure 3.

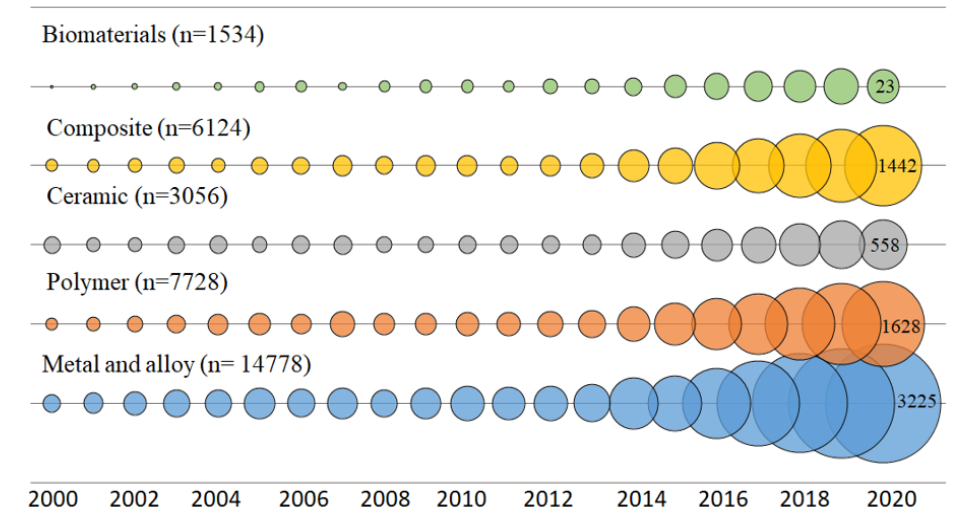

Figure 3. AM-material related scientific publications

The majority of the publications included in the analysis deal with metals and alloys. Polymers and composites were mentioned only half as often, followed by ceramics and biomaterials. For patent applications, a slightly different picture emerges.

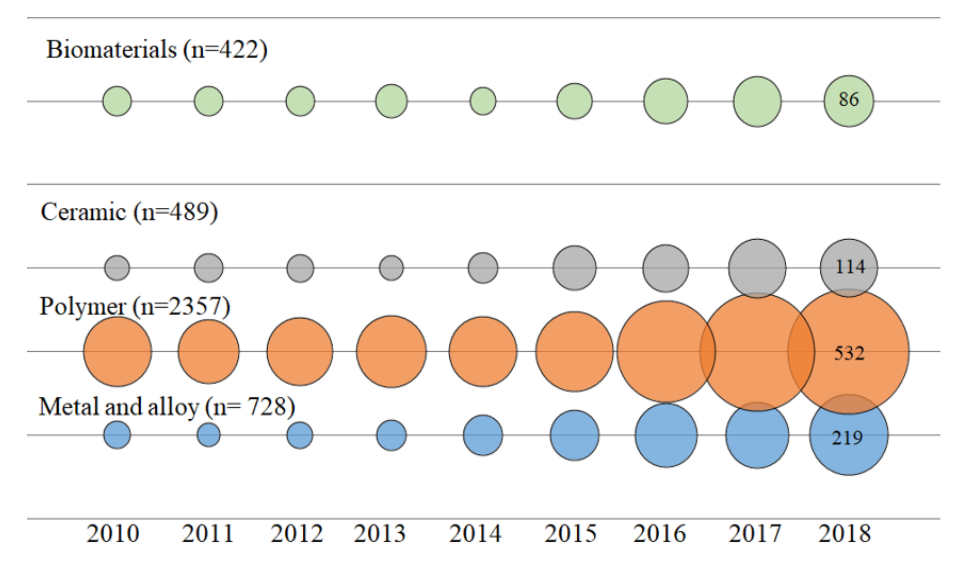

Figure 4. AM-material related patents 
Figure 4 shows the frequency of patent applications for the period 2010 to 2020. It should be noted that during data collection, composites were assigned to the respective groups according to their main components (Ceulemans et al., 2020).

688 companies surveyed in 2019 indicated that they wished to use the following materials with AM: standard alloys (40\%), high-performance polymer (35\%), standard or high-performance ceramics (31\%), high-performance alloys (31\%), tool steel (28\%), construction materials (21\%), standard polymer (17\%), other (13\%), pharmaceuticals $(11 \%)$, food (10\%) and tissue and live cells (7\%) (Ernst \& Young Global Limited, 2019).

While already a large number of polymers is listed in relevant databases (Tan et al., 2020), current research concentrates on a mixture of different materials to form alloys or composites (Piticescu et al., 2019). Fibre-reinforced composites have become an important research topic (Goh et al., 2018) and an increasing number of research projects focus on the development of new materials. The development of high-performance polymers or composites (such as ULTEM, PEEK PEKK - for dental implants) is crucial to support the transition of AM technology from prototyping to advanced applications (Haleem and Javaid, 2019). The increasing awareness for sustainable development is reflected by research addressing eco-friendly materials (Palanikumar et al., 2020), biodegradable polymers (Puppi and Chiellini, 2020) and metals (Qin and Wen, 2019), or sustainable use (Machado et al., 2019; Colorado et al., 2020). Further research is carried out in the area of multi-materials and composites, which allow 3D printed structures to change their shape and, most recently, also its function with time in response to external stimuli (Kuang et al., 2019; Ryan et al., 2021) - therefor called 4D-Printing. Based on advancements in multi-material AM, different methods of designing digital materials (functionally graded materials) (Loh et al., 2018) also on voxel-level are in the current focus (Salcedo et al., 2018).

\subsubsection{Digital Process Chain}

In addition to selecting the AM process and material, the process flow is strongly influenced by the handling of the digital product representation. The tools used in the digital process chain depend on the needs and requirements of both the actual product and the selected process (Attaran, 2020; Heerden, 2020). The AM processes can vary significantly in their mode of execution. Material selection is also non-trivial in this context. The increasing complexity of the shape of the products also makes the process more comprehensive. The digital technologies used thus provide a link between all the aspects considered above. In this context, digital technology includes all tools that are used in the preparation of the AM process to create, process and edit the digital representation of the product.

The print preparation software serves as an interface between the digital representation of the product and the AM production process. This includes both adaptations of process parameters and simulation of processes (Gibson et al., 2015).

One current field of research is the simulation of time-dependent processes (4D-Printing). The term "programmable mechanical metamaterial" is an example of this and implies the extension of digitality for the interface of the component with the process and materials (Tao et al., 2020).

With the help of so-called generator systems such as CAD, the digital geometry of the product is created. In addition to a conventional redesign of components, physically existing objects can, for example, be converted into a digital contour by means of scanning (Gibson et al., 2015). The availability and quality of surface recirculation tools have been addressed by Chen et al. (2020). Current conventional CAD systems cannot fully exploit the potentials arising from manufacturing with AM (Reiher, 2020) and are therefore supplemented by enhancement tools. Tools for the creation of lattice structures (Dalpadulo et al., 2020) or for topology optimisation (TO) are worth mentioning. These represent the subject of current research. Furthermore, it can be observed that there is an increasing integration of these additional tools into CAD systems.

A further research area that tends to support the use of AM is the generative design (Marinov et al., 2019). Here tools such as TO and AI (artificial intelligence) are brought together to be able to generate a variety of design proposals using design guidelines (Tyflopoulos et al., 2018). In addition to technological enablers such as machine learning, AI also plays a role in closing the gap in the understanding of $\mathrm{AM}$ as a digital manufacturing process compared to conventional processes (Charles et al., 2021). 


\subsubsection{Methodology}

The use of AM requires the consideration of many aspects ranging from process-related or material related aspects as well as decisions influenced by digital tools. These include, e.g. the selection of suitable manufacturing technologies, material selection, layer thickness, placement of support structures (if required), the orientation of the component while manufacturing and post-processing steps (depending on the process and product requirements) (Hinchy, 2019). Thus, designers need to be knowledgeable about AM processes and materials to design products and parts that make use of the advantages of AM (Gibson et al., 2015). Currently, a lack of knowledge is seen as a major barrier to exploiting the full potential of AM technology (Doubrovski et al., 2011; Borgue et al., 2018; Abdulhameed et al., 2019).

Keywords, topics, approaches and definitions for DfAM were identified based on the categorisation of different types of design support proposed by Gericke et al. (2017). The categorisation includes methodology, design process, design method, design guideline, design standard and tool.

In this part of the paper, different approaches are presented that aim to facilitate Design for AM (DfAM). DfAM is the methodical support for designers that aim at optimising the product design to deal with the complexity of the production in terms of the goals and benefits that result from these (Vaneker et al., 2020).

Research in the field of DfAM has been growing rapidly. An overview of the topic is also given by scientists like (Durakovic 2018; Pradel et al., 2018; Wiberg et al., 2019). DfAM approaches can be distinguished into heuristics, principles, guidelines, rules, process guidelines, specifications and process selection tools (Pradel et al., 2018). In the following paragraph, these categories are explained, and selected publications are referenced to guide further reading.

- AM heuristics are directives, mostly not validated but based on experience, for a fast but not necessarily optimal solution for the implementation of AM in the design process, e.g. (BlöschPaidosh and Shea, 2019; Mahan et al., 2020).

- AM principles are directional but not very restrictive. They are, therefore, more likely to support the creative phases of conceptualisation than the specific case of application. They are derived from a large pool of experience or empirically, e.g. (Lauff et al., 2019; Valjak and Bojčetić, 2019).

- AM guidelines provide context-dependent statements that are empirically tested or based on extensive experience and are more restrictive and less general than principles, e.g. (Lauff et al., 2019; Valjak and Bojčetić, 2019).

- AM rules are reliable statements derived from quantitative studies that relate to the expression of features (wall thickness, radii, etc.), e.g. (Haney et al., 2020; Schmidt and Zimmermann, 2020).

- $\quad$ AM process guidelines are information for the printing process (e.g. machine parameters and post-processing processes). They have less influence on the design process itself, but awareness of them during the design process can be beneficial to the final result, e.g. (Moritzer et al., 2019; Dietemann et al., 2020).

- AM specifications provide information about the characteristics of the printing process that should describe the quality of the result. This can include machine capabilities (e.g., layer thickness) or mechanical properties of the materials ((Xiong et al., 2015), often provided by manufacturers).

- $\quad$ AM process selection tools include methods to assist in the selection between conventional processes and AM and within different AM processes, e.g. (Meisel et al., 2016; Wortmann et al., 2019; Dohale et al., 2021).

Other categorisations of DfAM approaches refer, e.g. to the utilisation of process-independent potentials (opportunity-driven, e.g. design freedom), to the consideration of restrictions (restrictive driven, e.g. material parameters, manufacturability) (Laverne et al., 2015; Pradel et al., 2018; Dordlofva and Törlind, 2020), and dual DfAM. Dual DfAM is a compromise between the two previously mentioned (Laverne et al., 2015).

Ponche et al. (2012) note that decisions on the adaptation may vary over time. For example, assessing the suitability of AM based on a finished CAD model (spatial approach) will differ from an assessment that starts from functional specifications and a chosen manufacturing process (global approach).

Hällgren et al. (2016)) suggest a division of the approaches into process-driven (PD) and designerdriven (DD). While PD approaches aim to reduce the designer's interaction with the process (e.g. through topology optimisation), DD approaches aim to use the designer's knowledge of the process (e.g. adapting the geometry specifically for a process). 
Figure 4 shows the tendencies of the categories mentioned by Pradel to take restrictions or opportunities more into account. Furthermore, the connection to the AM procedure ultimately increases from left to right. While heuristics only give hints for an adequate implementation of $\mathrm{AM}$, the procedure is already established for specifications and after the application of "process selection tools".

\begin{tabular}{|c|c|c|c|c|c|c|}
\hline $\begin{array}{l}\text { Design } \\
\text { heuristics }\end{array}$ & $\begin{array}{l}\text { Design } \\
\text { principles }\end{array}$ & $\begin{array}{l}\text { Design } \\
\text { guidelines }\end{array}$ & Design rules & $\begin{array}{l}\text { Process } \\
\text { guidelines }\end{array}$ & Specifications & $\begin{array}{l}\text { Process } \\
\text { selection tools }\end{array}$ \\
\hline & & & & & \multicolumn{2}{|c|}{ Restriction/Limitation } \\
\hline \multicolumn{3}{|c|}{ Opportunities } & & & & \\
\hline & & & rocess orientation & & & \\
\hline
\end{tabular}

Figure 4. DfAM typology

Wilberg et al. (2019) mention that the criteria listed are often implemented by or in cooperation with methods and tools. Tools can be a technological enabler for digital processes such as topology optimisation or other types of design support.

Furthermore, methods can be used to adapt the form and function of a component-specific to the application of AM. In this regard, approaches are concerned with adapting existing methods for the targeted implementation of the functional architecture for the application of AM. This holistic adaptation of components can be seen as a global approach of "Dual DfAM". Here, function modelling plays a crucial role. Doubrovski et al. (2011) propose the application of Olsen's three-link chain model 3LCM for targeted functional modelling of additively printed components. A different example shows the adaptation of a component from the aerospace sector to the conditions of AM, using Enhanced FunctionMeans modelling (EF-M). The example has demonstrated that understanding the product architecture can support the designer in the question of where the use of AM makes sense (Borgue et al., 2018).

\section{DISCUSSION AND CONCLUSION}

In the period from 2000 to 2020 , the AM landscape changed significantly. The use of additive manufacturing processes has developed from the application area of pure prototyping to the manufacturing of functional objects. This is also reflected in related research activities and publications. After 2013 they showed an enormous increase. 80\% of the AM-related scientific publications (including Rapid prototyping) have been written in the period after 2011.

AM processes and associated machinery are continually evolving. Therefore, we see an increasing variety of different and also faster and more reliable machines. In addition, a transfer from high-end industrial components to smaller desktop devices is being recognised. The increased quality of the printed parts allows a cost-effective entry into the additive mass production of functional components. However, some barriers on the way to integration into industrial production remain. A number of new research areas have developed in this field, for example, in the area of pre-and post-processing, hybrid $\mathrm{AM}$, or monitoring processes. Current developments in the area of AM processes, such as multimaterial printing, open up new opportunities, including digital materials and functionally grade products, resulting in new trends, e.g. 4D printing. A remaining barrier for a broader industrial uptake of AM is currently the high costs of materials and machines, especially in the area of metal printing.

The primary trend found in the material section was a greater diversification of available AMmaterials, with recent developments in all material classes. An important research area is composites and hybrid materials. Based on that, a new segment evolved and first commercially fibre-reinforced printers were offered in 2019. Furthermore, research in the field of high-performance materials or biomaterials drives the transition from prototyping to industrial application.

Developments in processes and materials have triggered substantial development and research in the field of digital processes. This includes supporting tools for the creation of lattice structures, topology optimisation, generative design, but also supporting tools for reverse engineering and processing of scan data. Most of these applications have already found their way into the standard scope of services of the market-leading vendors of CAD systems. Advancements in the field of materials and processes triggered the development of tools that break new ground (voxel-based) in the modelling of materials.

The lack of knowledge is still an important reason why the potential of AM is not yet fully exploited. Charles et al. (2021) relate this gap in knowledge to the relatively short period in which it is being 
used and sees an opportunity to close this gap through technological enablers such as AI and machine learning. Furthermore, tools of the digital process chain help in further exploiting potentials of AM, e.g. topology optimisation or design support for lightweight structures such as lattice structures. However, these tools can also be a source of uncertainty for designers if not properly addressing the needs of designers.

A barrier for providing better support, thus enabling wider use of AM, is caused by the continuous evolution of processes and materials, which affect the suitability of available design support. While existing tools, often integrated into proprietary software, facilitate embodiment design, detail design and manufacturing, support for the conceptual design stage is scarce.

However, at this stage, design support would have a considerable effect as AM potentials (e.g. lightweight design or functional integration) can be implemented very effectively at this stage.

Currently, the whole field is shaped by a technological push materialising in new materials and machines and processes. However, the working practices and needs of designers as enablers for improved AM-based design (pull) are currently not sufficiently investigated.

\section{REFERENCES}

Abdulhameed, O., Al-Ahmari, A., Ameen, W. and Mian, S. H. (2019) 'Additive manufacturing: Challenges, trends, and applications', Advances in Mechanical Engineering, SAGE Publications Inc., 11(2). https://dx. doi.org/10.1177/1687814018822880.

Allison, A. and Scudamore, R. (2013) Additive Manufacturing: Strategic Research Agenda.

AMFG (2020) The Additive Manufacturing Landscape 2020 Table of Contents.

Anderson, C. (2012) Makers: The New Industrial Revolution. Crown Business.

ASTM International (2012) ASTM F2792 - 12a Standard Terminology for Additive Manufacturing Technologies. West Conshohocken, PA.

ASTM International (2017) DIN EN ISO/ASTM 52900. Additive manufacturing - General principles Terminology

Attaran, M. (2020) 'Digital technology enablers and their implications for supply chain management', Supply Chain Forum. Taylor and Francis Ltd., pp. 158-172. https://dx.doi.org/10.1080/16258312.2020.1751568.

Beaman, J. J., Atwood, C., Bergman, T. L., Bourell, D., Hollister, S. and Rosen, D. (2004) WTEC Panel Report on Additive/Subtractive Manufacturing Research and Development in Europe. Baltimore.

Blösch-Paidosh, A. and Shea, K. (2019) 'Design Heuristics for Additive Manufacturing Validated Through a User Study1', Journal of Mechanical Design, Transactions of the ASME. American Society of Mechanical Engineers (ASME), 141(4). https://dx.doi.org/10.1115/1.4041051.

Borgue, O., Muller, J., Panarotto, M. and Isaksson, O. (2018) Function modelling and constraints replacement to support design for additive manufacturing of satellite components, Proceedings of NordDesign: Design in the Era of Digitalization, 2018

Bourell, D. L., Leu, M. C. and Rosen, D. W. (2009) Roadmap for Additive Manufacturing Identifying the Future of Freeform Processing. Austin.

Ceulemans, J., Ménière, Y., Nichogiannopoulou, A., Rodríguez, J. P., Rudyk, I. (2020) 'Patents and additive manufacturing', European Patent Office.

Charles, A., Salem, M., Moshiri, M., Elkaseer, A. and Scholz, S. G. (2021) 'In-process digital monitoring of additive manufacturing: Proposed machine learning approach and potential implications on sustainability', in Smart Innovation, Systems and Technologies. Springer, pp. 297-306. https://dx.doi.org/10.1007/978-98115-8131-1_27.

Chen, F., Zabalza, J., Murray, P., Marshall, S., Yu, J. and Gupta, N. (2020) 'Embedded product authentication codes in additive manufactured parts: Imaging and image processing for improved scan ability', Additive Manufacturing. Elsevier BV, 35. https://dx.doi.org/10.1016/j.addma.2020.101319.

Colorado, H. A., Velásquez, E. I. G. and Monteiro, S. N. (2020) 'Sustainability of additive manufacturing: the circular economy of materials and environmental perspectives', Journal of Materials Research and Technology, 9(4), pp. 8221-8234. https://dx.doi.org/10.1016/j.jmrt.2020.04.062.Levy

Dalpadulo, E., Pini, F. and Leali, F. (2020) 'Integrated CAD platform approach for Design for Additive Manufacturing of high performance automotive components', International Journal on Interactive Design and Manufacturing. Springer, 14(3), pp. 899-909. https://dx.doi.org/10.1007/s12008-020-00684-7.

Dietemann, B., Bosna, F., Lorenz, M., Travitzky, N., Kruggel-Emden, H., Kraft, T. and Bierwisch, C. (2020) 'Modeling robocasting with smoothed particle hydrodynamics: Printing gap-spanning filaments', Additive Manufacturing. Elsevier BV, 36. https://dx.doi.org/10.1016/j.addma.2020.101488.

Dohale, V., Akarte, M., Gupta, S. and Verma, V. (2021) 'Additive Manufacturing Process Selection Using MCDM', in Lecture Notes in Mechanical Engineering. Springer, pp. 601-609. https://dx.doi.org/10.1007/ 978-981-15-3639-7_72. 
Dordlofva, C. and Törlind, P. (2020) 'Evaluating design uncertainties in additive manufacturing using design artefacts: Examples from space industry’, Design Science. Cambridge University Press, 6. https://dx.doi.org/10.1017/dsj.2020.11.

Doubrovski, Z., Verlinden, J. C. and Geraedts, J. M. P. (2011) 'Optimal design for additive manufacturing: Opportunities and challenges', in Proceedings of the ASME Design Engineering Technical Conference, pp. 635-646. https://dx.doi.org/10.1115/DETC2011-48131.

Durakovic, B. (2018) 'Design for additive manufacturing: Benefits, trends and challenges', Periodicals of Engineering and Natural Sciences. International University of Sarajevo, 6(2), pp. 179-191. https://dx. doi.org/10.21533/pen.v6i2.224.

Ehrenberg, N. (2013) From Powders to Finished Parts. Available at: http://www.siemens.com/innovation/apps/ pof_microsite/_pof-spring-2013/_html_en/laser-melting.html.

Ernst \& Young Global Limited (2019) ‘3D printing: hype or game changer? - A Global EY Report 2019', p. 64.

François, M., Segonds, F., Rivette, M., Turpault, S. and Peyre, P. (2019) 'Design for additive manufacturing (DfAM) methodologies: a proposal to foster the design of microwave waveguide components', Virtual and Physical Prototyping. Taylor and Francis Ltd., 14(2), pp. 175-187. https://dx.doi.org/10.1080/17452759. 2018.1549901.

Gausemeier, J., Echterhoff, N., Kokoschka, M. and Wall, M. (2011) Thinking ahead the Future of Additive Manufacturing - Analysis of Promising Industries. Paderborn.

Gebhardt, A. (2011) Generative Fertigungsverfahren. München: Carl Hanser Verlag. https://dx.doi.org/10.3139/ 9783446436527.

Gebhardt, A. and Hötter, J.-S. (2016) Additive Manufacturing: 3D Printing for Prototyping and Manufacturing, Carl Hanser Verlag. ISBN 9783446452367

Gericke, K., Eckert, C. and Stacey, M. (2017) 'What do we need to say about a design method?', in Proceedings of the International Conference on Engineering Design, ICED. The Design Society, Glasgow.

Gibson, I., Rosen, D. and Stucker, B. (2015) Additive manufacturing technologies: 3D printing, rapid prototyping, and direct digital manufacturing, second edition, Additive Manufacturing Technologies: $3 D$ Printing, Rapid Prototyping, and Direct Digital Manufacturing, Second Edition. Springer New York. https://dx.doi.org/10.1007/978-1-4939-2113-3.

Goh, G. D., Dikshit, V., Nagalingam, A. P., Goh, G. L., Agarwala, S., Sing, S. L., Wei, J. and Yeong, W. Y. (2018) 'Characterisation of mechanical properties and fracture mode of additively manufactured carbon fibre and glass fibre reinforced thermoplastics', Materials \& Design, 137, pp. 79-89. https://dx.doi.org/10.1016/j. matdes.2017.10.021.

Gorn, M., Cerwenka, G., Gralow, M. and Emmelmann, C. (2019) 'Industrial 3D printing for modern machine and handling systems-Potential and solutions', Journal of Laser Applications. Laser Institute of America, 31(2), p. 022309. https://dx.doi.org/10.2351/1.5096098.

Haleem, A. and Javaid, M. (2019) 'Polyether ether ketone (PEEK) and its manufacturing of customised 3D printed dentistry parts using additive manufacturing', Clinical Epidemiology and Global Health, 7(4), pp. 654-660. https://dx.doi.org/10.1016/j.cegh.2019.03.001.

Hällgren, S., Pejryd, L. and Ekengren, J. (2016) '(Re)Design for Additive Manufacturing', in Procedia CIRP. Elsevier BV, pp. 246-251. https://dx.doi.org/10.1016/j.procir.2016.04.150.

Haney, R., Tran, P., Trigg, E. B., Koerner, H., Dickens, T. and Ramakrishnan, S. (2020) 'Printability and performance of 3D conductive graphite structures', Additive Manufacturing, Elsevier B.V. https://dx.doi.org/10.1016/j.addma.2020.101618.

Van Heerden, A., Grobbelaar, S. S. and Sacks, N. (2020) 'The impact of digitalisation and additive manufacturing on business models and value chains: A scoping review', in Towards the Digital World and Industry X.O - Proceedings of the 29th International Conference of the International Association for Management of Technology, IAMOT 2020. University of Pretoria, pp. 1292-1309.

Heikkinen, T., Johansson, J. and Elgh, F. (2018) 'Review of CAD-model capabilities and restrictions for multidisciplinary use', Computer-Aided Design and Applications. CAD Solutions, LLC, 15(4), pp. 509519. https://dx.doi.org/10.1080/16864360.2017.1419639.

Hinchy, E. P. (2019) 'Design for Additive Manufacturing', in Polymer-Based Additive Manufacturing. Cham: Springer International Publishing, pp. 23-50. https://dx.doi.org/10.1007/978-3-030-24532-0_2.

Kessler, A., Hickel, R. and Reymus, M. (2020) '3D printing in dentistry-state of the art', Operative Dentistry, 45(1), pp. 30-40. https://dx.doi.org/10.2341/18-229-L.

Kuang, X., Roach, D. J., Wu, J., Hamel, C. M., Ding, Z., Wang, T., Dunn, M. L. and Qi, H. J. (2019) 'Advances in 4D Printing: Materials and Applications’, Advanced Functional Materials, 29(2), p. 1805290. https://dx.doi.org/10.1002/adfm.201805290.

Kussmaul, R., Biedermann, M., Pappas, G. A., Jónasson, J. G., Winiger, P., Zogg, M., Türk, D.-A., Meboldt, M. and Ermanni, P. (2019) 'Individualised lightweight structures for biomedical applications using additive manufacturing and carbon fibre patched composites', Design Science, 5, p. e20. https://dx.doi.org/10. 1017/dsj.2019.19. 
Lauff, C. A., Blake Perez, K., Camburn, B. A. and Wood, K. L. (2019) 'Design principle cards: Toolset to support innovations with additive manufacturing', in Proceedings of the ASME Design Engineering Technical Conference. American Society of Mechanical Engineers (ASME). https://dx.doi.org/10.1115/ DETC2019-97231.

Laverne, F., Segonds, F., Anwer, N. and Le Coq, M. (2015) 'Assembly based methods to support product innovation in design for additive manufacturing: An exploratory case study', Journal of Mechanical Design, Transactions of the ASME. American Society of Mechanical Engineers (ASME), 137(12). https://dx.doi.org/10.1115/1.4031589.

Loh, G. H., Pei, E., Harrison, D. and Monzón, M. D. (2018) 'An overview of functionally graded additive manufacturing', Additive Manufacturing, 23, pp. 34-44. https://dx.doi.org/10.1016/j.addma.2018.06.023.

Lowke, D., Dini, E., Perrot, A., Weger, D., Gehlen, C. and Dillenburger, B. (2018) 'Particle-bed 3D printing in concrete construction - Possibilities and challenges', Cement and Concrete Research, 112, pp. 50-65. https://dx.doi.org/10.1016/j.cemconres.2018.05.018.

Machado, C. G., Despeisse, M., Winroth, M. and da Silva, E. H. D. R. (2019) 'Additive manufacturing from the sustainability perspective: proposal for a self-assessment tool', Procedia CIRP, 81, pp. 482-487. https://dx.doi.org/10.1016/j.procir.2019.03.123.

Mahan, T., Stover, M., Arguelles, A. and Menold, J. (2020) 'Creating a Design for Inspectability Framework: Investigating DfAM Heuristics for Inspection Technologies', in ASME International. https://dx.doi.org/10. 1115/detc2020-22601.

Marinov, M., Amagliani, M., Barback, T., Flower, J., Barley, S., Furuta, S., Charrot, P., Henley, I., Santhanam, N., Finnigan, G. T., Meshkat, S., Hallet, J., Sapun, M. and Wolski, P. (2019) 'Generative Design Conversion to Editable and Watertight Boundary Representation', CAD Computer Aided Design. Elsevier Ltd, 115, pp. 194-205. https://dx.doi.org/10.1016/j.cad.2019.05.016.

Markets\&Markets (2019) 2020 Additive Manufacturing Market Outlook and Summary of Opportunities.

Meisel, N. A., Williams, C. B., Ellis, K. P. and Taylor, D. (2016) 'Decision support for additive manufacturing deployment in remote or austere environments', Journal of Manufacturing Technology Management. Emerald Group Publishing Ltd., 27(7), pp. 898-914. https://dx.doi.org/10.1108/JMTM-06-2015-0040.

Moritzer, E., Hirsch, A. and Bürenhaus, F. (2019) 'Development and modelling of design and process guidelines for FDM structures for the partial reinforcement of hybrid structures', in AIP Conference Proceedings. American Institute of Physics Inc. https://dx.doi.org/10.1063/1.5088314.

Ngo, T. D., Kashani, A., Imbalzano, G., Nguyen, K. T. Q. and Hui, D. (2018) 'Additive manufacturing (3D printing): A review of materials, methods, applications and challenges', Composites Part B: Engineering. Elsevier Ltd, pp. 172-196. https://dx.doi.org/10.1016/j.compositesb.2018.02.012.

Palanikumar, K., Mudhukrishnan, M., Soorya Prabha, P. (2020) 'Technologies in additive manufacturing for fibre reinforced composite materials: a review', Current Opinion in Chemical Engineering, 28, pp. 51-59. https://dx.doi.org/10.1016/j.coche.2020.01.001.

Parthasarathy, J., Starly, B. and Raman, S. (2011) 'A design for the additive manufacture of functionally graded porous structures with tailored mechanical properties for biomedical applications', Journal of Manufacturing Processes. Elsevier Ltd, 13(2), pp. 160-170. https://dx.doi.org/10.1016/j.jmapro.2011.01.004.

Piticescu, R., Vlaicu, I., Katz-Demyanetz, A., Popov, V. V., Kovalevsky, A., Safranchik, D. and Koptyug, A. (2019) 'Powder-bed additive manufacturing for aerospace application: Techniques, metallic and metal/ceramic composite materials and trends', Manufacturing Review, 6. https://dx.doi.org/10.1051/mfreview/2019003.

Ponche, R., Hascoet, J. Y., Kerbrat, O. and Mognol, P. (2012) 'A new global approach to design for additive manufacturing', Virtual and Physical Prototyping, 7(2), pp. 93-105. https://dx.doi.org/10.1080/17452759. 2012.679499.

Pradel, P., Zhu, Z., Bibb, R. and Moultrie, J. (2018) 'A framework for mapping design for additive manufacturing knowledge for industrial and product design', Journal of Engineering Design, 29(6), pp. 291-326. https://dx.doi.org/10.1080/09544828.2018.1483011.

Puppi, D. and Chiellini, F. (2020) 'Biodegradable Polymers for Biomedical Additive Manufacturing', Applied Materialstoday, 20. https://dx.doi.org/10.1016/j.apmt.2020.100700.

Qin, Y. and Wen, P. (2019) 'Additive manufacturing of biodegradable metals: Current research status and future perspectives’, Acta Biomaterialia, 98. https://dx.doi.org/10.1016/j.actbio.2019.04.046.

Reiher, T., Vogelsang, S. and Koch, R. (2020) 'Computer integration for geometry generation for product optimisation with Additive Manufacturing', in Solid Freeform Fabrication 2017: Proceedings of the 28th Annual International Solid Freeform Fabrication Symposium - An Additive Manufacturing Conference, SFF 2017. The University of Texas at Austin, pp. 903-921.

RepRap, (2013). Available at: http://reprap.org/.

Royal Academy of Engineering (2013) Additive manufacturing: opportunities and constraints. London.

Ryan, K. R., Down, M. P. and Banks, C. E. (2021) 'Future of additive manufacturing: Overview of 4D and 3D printed smart and advanced materials and their applications', Chemical Engineering Journal. Elsevier B.V. https://dx.doi.org/10.1016/j.cej.2020.126162. 
Salcedo, E., Baek, D., Berndt, A. and Ryu, J. E. (2018) 'Simulation and validation of three-dimension functionally graded materials by material jetting', Additive Manufacturing, 22, pp. 351-359. https://dx.doi.org/10. 1016/j.addma.2018.05.027.

Schmidt, K. and Zimmermann, A. (2020) 'Evaluation of process and anisotropy of thermosetting adhesives with ultraviolet-assisted 3D dispensing', Additive Manufacturing. Elsevier BV, 34. https://dx.doi.org/10.1016/ j.addma.2020.101262.

Sculpteo (2020) The state of $3 D$ Printing.

Senvol Database, S. (2020) Senvol Material Database.

Tan, L. J., Zhu, W. and Zhou, K. (2020) 'Recent Progress on Polymer Materials for Additive Manufacturing', Advanced Functional Materials, 30(43), p. 2003062. https://dx.doi.org/10.1002/adfm.202003062.

Tao, R., Xi, L., Wu, W., Li, Y., Liao, B., Liu, L., Leng, J. and Fang, D. (2020) '4D printed multi-stable metamaterials with mechanically tunable performance', Composite Structures. Elsevier Ltd., 252. https://dx.doi.org/10.1016/j.compstruct.2020.112663.

Tofail, S. A. M., Koumoulos, E. P., Bandyopadhyay, A., Bose, S., O’Donoghue, L. and Charitidis, C. (2018) 'Additive manufacturing: scientific and technological challenges, market uptake and opportunities', Materials Today, 21(1), pp. 22-37. https://dx.doi.org/10.1016/j.mattod.2017.07.001.

Tyflopoulos, E., Flem, D. T., Steinert, M. and Olsen, A. (2018) 'State of the art of generative design and topology optimisation and potential research needs', in Proceedings of NordDesign: Design in the Era of Digitalization, NordDesign 2018. The Design Society.

Valdes, Y. M. I. R. J. (2017) 'Patents and the Fourth Industrial Revolution (EPO)', European Patent Office, Handelsblatt Research Institute, (December), p. 100.

Valjak, F. and Bojčetić, N. (2019) 'Conception of design principles for additive manufacturing', in Proceedings of the International Conference on Engineering Design, ICED. Cambridge University Press, pp. 689-698. https://dx.doi.org/10.1017/dsi.2019.73.

Vaneker, T., Bernard, A., Moroni, G., Gibson, I. and Zhang, Y. (2020) 'Design for additive manufacturing: Framework and methodology', CIRP Annals. Elsevier USA, 69(2), pp. 578-599. https://dx.doi.org/10. 1016/j.cirp.2020.05.006.

De Vere, I. (2013) 'Industrial design 2.0: a renaissance', in Lawlor, J., Reilly, G., Simpson, R., Ring, M., Kovacevic, A., McGrath, M., Ion, W., Torney, D., Bohemia, E., McMahon, C., and Parkinson, B. (eds) Proceedings of International Conference on Engineering and Product Design Education. Dublin: The Design Society, Glasgow, pp. 824-829.

Wiberg, A., Persson, J. and Ölvander, J. (2019) 'Design for additive manufacturing - a review of available design methods and software', Rapid Prototyping Journal. Emerald Group Publishing Ltd., pp. 1080-1094. https://dx.doi.org/10.1108/RPJ-10-2018-0262.

Wortmann, N., Jürgenhake, C., Seidenberg, T., Dumitrescu, R. and Krause, D. (2019) 'Methodical approach for process selection in additive manufacturing', in Proceedings of the International Conference on Engineering Design, ICED. Cambridge University Press, pp. 779-788. https://dx.doi.org/10.1017/dsi.2019.82.

Xiong, J., Zhang, G. and Zhang, W. (2015) 'Forming appearance analysis in multi-layer single-pass GMAWbased additive manufacturing', International Journal of Advanced Manufacturing Technology. Springer London, 80(9-12), pp. 1767-1776. https://dx.doi.org/10.1007/s00170-015-7112-4.

Yang, S., Tang, Y. and Zhao, Y. F. (2015) 'A new part consolidation method to embrace the design freedom of additive manufacturing', Journal of Manufacturing Processes. Elsevier Ltd, 20, pp. 444-449. https://dx.doi.org/10.1016/j.jmapro.2015.06.024.

Zhang, B., Jaiswal, P., Rai, R. and Nelaturi, S. (2018) 'Additive Manufacturing of Functionally Graded Material Objects: A Review', Journal of Computing and Information Science in Engineering, 18(4). https://dx.doi.org/10.1115/1.4039683. 